\title{
ciudad del este
}

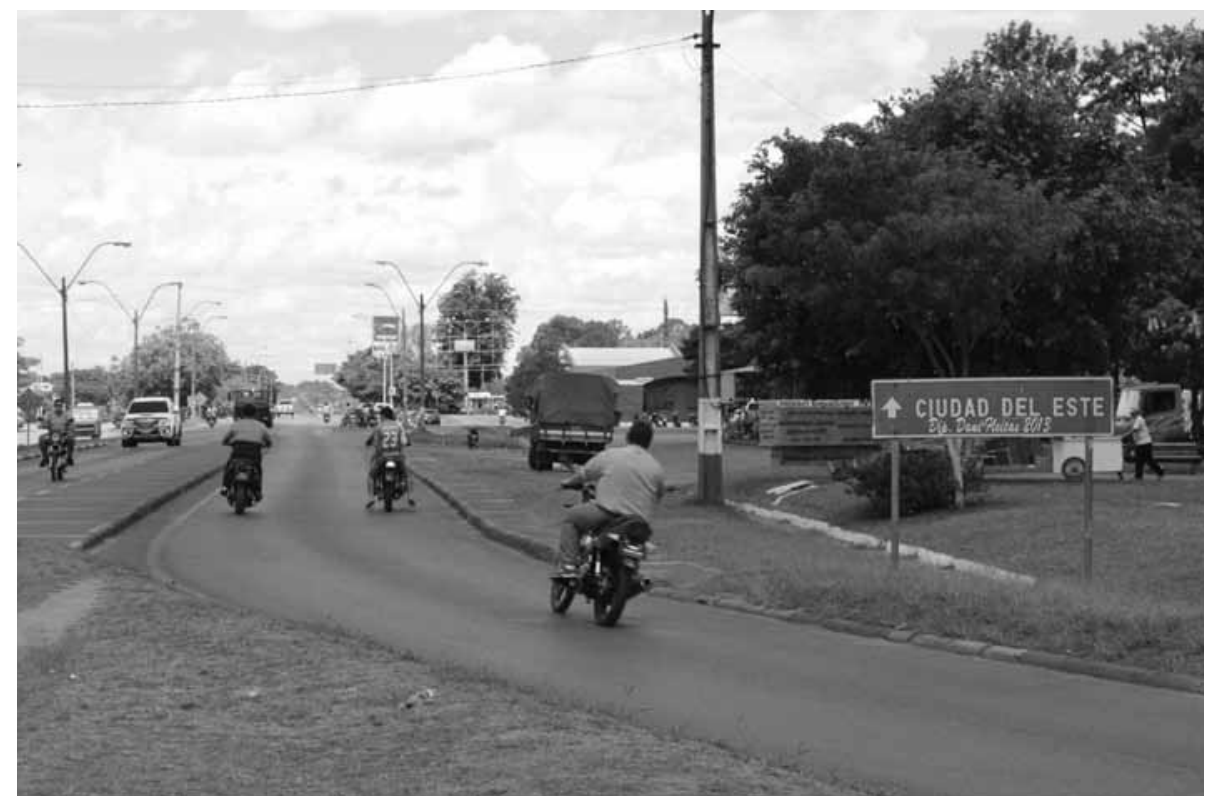

Foto: Carlos Freire da Silva

Caaguazú, placa indica o rumo de Ciudad del Este.

\section{Ciudad del Este Do comércio de fronteira ao centro de São Paulo}

\author{
Carlos Freire da Silva*
}

No dia 27 de março de 1965 foi inaugurada a famosa Ponte da Amizade que faz a ligação entre Paraguai e Brasil, passando sobre o rio Paraná. Na cerimônia estavam presentes os presidentes de ambos os países, nos dois casos militares que haviam sido alçados ao poder através de golpes de Estado, respectivamente, o general Alfredo Stroessner e o marechal Castello Branco. Ambos caminharam para selar as mãos exatamente no meio da ponte ${ }^{1}$. Construída pelo Departamento Nacional de Estradas e Rodagens (DNER) do governo brasileiro, teria mais de meio quilômetro de extensão e, na época, era considerada o maior vão livre em

\footnotetext{
* Pesquisador, doutor em Sociologia pela USP.
} 
concreto armado do mundo. A inauguração da ponte da Amizade marcaria a consolidação da política de reaproximação entre os dois países, após um longo período de pouca ligação desde a guerra do Paraguai.

Compondo a região da tríplice fronteira com a cidade de Puerto Iguazu, do lado Argentino, a ponte da Amizade liga Ciudad del Este, no lado paraguaio, à Foz do Iguaçu, no lado brasileiro e, a partir de sua inauguração, marcaria profundamente o desenvolvimento de ambas as cidades e da própria história das relações entre Paraguai e Brasil. Desde então, muita coisa se passou através da Ponte da Amizade, e a consolidação do comércio de Ciudad del Este é algo que informa extensamente as imagens construídas sobre o país vizinho. Uma vasta gama de representações com maior ou menor base real ou imaginada sobre o comércio fronteiriço constrói uma imagem sobre o Paraguai e os paraguaios. Geralmente, quando se fala sobre Paraguai no Brasil, as imagens mais imediatas são referentes à Ciudad del Este.

Embora poucos migrantes paraguaios em São Paulo sejam naturais de lá - a maior parte dos mais recentes são do departamento de Caaguazú, no centro do país, enquanto os grupos que estão aqui há mais tempo são, sobretudo, de Assunção e das cidades próximas - eles estão sujeitos aos preconceitos associados ao comércio fronteiriço. Isso a tal ponto que, em reação às constantes associações difundidas nos meios de comunicação brasileiros que ligam o Paraguai à ideia de falsificação e contrabando, foi fundada em 2009 uma associação de paraguaios e descendentes que visa a questionar estas colocações e difundir uma imagem positiva do Paraguai. Trata-se da "Paraguay Teete", que em guarani quer dizer autêntico, verdadeiro". Metáforas pejorativas e discriminatórias associam "do Paraguai" e "paraguaio" às ideias de contrabando, pirataria, falsificação e baixa qualidade. Trata-se de um olhar construído sobre o Paraguai que além de parcial e depreciativo, pouco informa sobre o próprio circuito comercial de Ciudad del Este, como ele se desenvolveu e as transformações recentes pelas quais este circuito vem passando.

O objetivo deste artigo é problematizar as imagens que se tem do Paraguai (e dos paraguaios) no Brasil a partir de representações sobre Ciudad del Este. Para tanto buscamos examinar como se deu o desenvolvimento desta dinâmica comercial, particularmente em sua relação com São Paulo, em torno da reaproximação diplomática entre os dois países, do turismo de compras dos sacoleiros brasileiros e de outras dinâmicas migratórias que ligam o desenvolvimento de Ciudad del Este e São Paulo, em especial através da migração chinesa e libanesa. Em cidades de fronteira, o desenvolvimento do comércio baseado nas vantagens diferenciais entre países é algo bastante comum ${ }^{3}$; no caso de Ciudad del Este, a peculiaridade foi a escala desses fluxos, com milhares de pessoas que fizeram das idas e vindas uma forma de ganhar a vida, e a maneira como isto alimentou as representações sobre o país vizinho. Pelo fato deste processo ter ocorrido justamente em um momento marcado pela crescente globalização e a massificação do consumo, no Brasil se associou alguns aspectos 
desta dinâmica comercial ao Paraguai. No entanto, veremos que este processo remete a dinâmicas mais amplas de produção e circulação de mercadorias, nas quais Ciudad del Este se constituiu em um entreposto de triangulação durante algum período e do qual, atualmente, São Paulo vem ganhando centralidade.

\section{A formação de Ciudad del Este como polo comercial ${ }^{4}$}

Ciudad del Este é a segunda cidade mais populosa do Paraguai com 312.652 habitantes ${ }^{5}$, atrás apenas da capital do país. Situada a $334 \mathrm{~km}$ de Assunção, foi fundada em 1957 com o nome de Puerto Presidente Stroessner, e passaria a ter o nome atual apenas depois da queda do governo militar em 1989. Pode-se afirmar que a fundação do município foi induzida pela política de reaproximação entre os governos do Paraguai e do Brasil na década de 1950, após um longo período de distanciamento posterior à Guerra da Tríplice Aliança (1864-1870). Até então haviam sido poucas as relações após o conflito que redefiniu limites de fronteira entre os dois países. O Paraguai se voltou prioritariamente para a Argentina como principal parceiro comercial e como via de comunicação com o restante do mundo, através do Rio da Prata. A visita de Getúlio Vargas, em 1941, o primeiro presidente brasileiro a estar presente no país vizinho, foi um marco inicial desta reaproximação ${ }^{6}$. Em decorrência, foram realizados programas de intercâmbio cultural e militar, além das primeiras negociações para concessão de um porto franco ao Paraguai em território brasileiro. No entanto, a reaproximação se concretizaria apenas no período de Juscelino Kubitschek (1956-1961) e com a ascensão de Alfredo Stroessner à frente do governo paraguaio, a partir de 1954 (MENEZES, 1987; SILVA, 2006).

O golpe de Estado que acabou levando à ditadura militar do general Alfredo Stroessner diz muito sobre as peculiaridades da história política paraguaia. De acordo com o historiador Alfredo da Mota Menezes (1987), depois de uma guerra civil em que foram expulsos do país os membros do partido liberal e do partido febrerista em 1947, todas as disputas políticas passaram a se realizar apenas no interior do partido colorado, em um regime partidário único que perdurou até 1962. Segundo o historiador, em um período marcado por sucessivos golpes de Estado entre os próprios partidários colorados, Stroessner assumiu o governo. As divergências eram principalmente sobre a condução da política econômica externa: se alinhada à dependência da Argentina ou à tentativa de criação de uma alternativa junto ao Brasil. O golpe ocorreu justamente pouco antes de uma visita do presidente argentino, Juan Perón, ao Paraguai em 1954. Depois de destituído o presidente Federico Chávez, foi convocada uma eleição na qual Stroessner foi o único candidato. De acordo com Menezes, no governo militar, houve um afastamento em relação ao peronismo e a tudo que era pró-Argentina, o que marcou uma política de aproximação com o Brasil. Além disto, parte da 
formação militar de Stroessner fora realizada na Escola Superior de Guerra no Rio de Janeiro, o que pode ter facilitado esse alinhamento, principalmente depois de iniciada a ditadura militar brasileira.

A reaproximação com o Brasil viria primeiramente através da construção de estradas no oeste do Paraná e de facilidades alfandegárias para permitir ao Paraguai ter acesso franco ao porto de Paranaguá para desenvolver seu comércio exterior. $\mathrm{O}$ acordo incluía ainda a realização dos estudos para a abertura da rodovia e o financiamento de sua construção até Ciudad Coronel Oviedo, no centro do Paraguai (SILVA, 2006). Assim, o país teria uma alternativa para a importação e exportação marítima além da navegação do rio da Prata, com a consequente dependência da Argentina. A própria construção da Ponte da Amizade é uma das medidas ligadas à viabilização de uma rota alternativa do Paraguai para o Atlântico através do território brasileiro, cujo tratado de construção foi assinado em 1956, levando nove anos para ser concluída. Posteriormente, a reaproximação teve andamento com as negociações para a construção da usina hidroelétrica binacional Itaipu, cujo tratado de construção foi assinado em 1973, e sua conclusão ocorreu em 1983. A obra da usina marcou o desenvolvimento urbano tanto de Ciudad del Este como de Foz do Iguaçu. Mais de 30 mil operários brasileiros e paraguaios foram para a região trabalhar na obra (MENEZES, 1987). De acordo com Menezes, essas medidas contribuíram para que o Brasil acabasse substituindo a Argentina como principal parceiro comercial do Paraguai. $O$ desenvolvimento de Ciudad del Este também respondia a uma política de povoamento do leste do país empreendida por Stroessner, inspirada na doutrina de segurança nacional da ditadura militar no Brasil (PALAU, 2001).

A cidade foi fundada pouco menos de dois anos depois do tratado para a construção da ponte, a partir do ponto do rio no qual ela seria erguida e onde ficou definido que passaria a estrada. Nesta época, Foz do Iguaçu e Puerto Iguaçu já eram cidades estruturadas. Nos jornais dos anos 1970, Puerto Presidente Stroessner aparece nos anúncios de pacotes turísticos para as cataratas do Iguaçu oferecendo como atrativo o comércio de artigos importados de luxo com baixas taxas de impostos.

O antropólogo Fernando Rabossi (2004) desenvolveu uma pesquisa acerca das dinâmicas comerciais de Ciudad del Este. Segundo o pesquisador, desde a inauguração da Ponte da Amizade a cidade atraía turistas argentinos e brasileiros que visitavam as cataratas do Iguaçu em busca dos cassinos liberados, bem como o comércio de artigos importados em "regime especial de turismo". Diferentemente dos seus outros vizinhos, o Paraguai não teria seguido a política de industrialização por substituição de importações e, desde a década de 1950, teria eliminado taxas de exportação e reduzido os impostos de importação. Segundo Rabossi, Ciudad del Este teria a primeira concessão de zona franca ainda em 1960, de modo a definir um sistema que favorecia o comércio direcionado aos turistas estrangeiros. A partir disto, a cidade teria se desenvolvido como uma das maiores zonas francas do mundo, atrás apenas de Miami e Hong Kong. 
Ainda de acordo com Rabossi, entre o final dos anos 1970 e início dos anos 1980, ocorreu uma transmutação deste turismo de compras para consumo próprio em um circuito de compras para revenda, animado por milhares de sacoleiros, acompanhada também por alterações em relação aos produtos comercializados. $\mathrm{O}$ autor argumenta que no começo eram produtos originais e de qualidade, importados de Miami e destinados aos turistas. Nos anos 1980 aumentou o movimento de sacoleiros, pequenos comerciantes que buscavam mercadorias mais baratas para venderem em suas cidades de origem, e começam a aparecer marcas desconhecidas e cópias, produtos de menor qualidade e bem mais baratos, cada vez mais vindos diretamente da China continental (RABOSSI, 2004, p. 226).

Quando analisamos do lado brasileiro, um dos fatores que teria impulsionado a dinâmica dos sacoleiros para Ciudad del Este teria sido a política de taxação da importação dos produtos supérfluos implementada durante o regime militar. Quando o chamado "milagre econômico" dava seus primeiros sinais de esgotamento nos anos 1970 e em decorrência do déficit cambial causado pela crise do petróleo, o governo militar brasileiro implementou medidas restritivas para tentar conter a evasão de divisas e dificultar a saída de dólares do país. A partir de 1974, a importação de tudo que não era classificado como bem de capital era sobretaxado em 100\%, sendo que em 1981 o imposto foi novamente elevado e chegou a $200 \%$ do valor dos bens considerados supérfluos. Combinado com as facilidades de importação proporcionadas em Ciudad del Este, a sobretaxação aos supérfluos criou uma grande vantagem diferencial de preços entre os dois lados da fronteira para quem se dispunha a trazer as mercadorias (FREIRE DA SILVA, 2014).

A partir dessas circunstâncias, milhares de pessoas fizeram da exploração desse diferencial um modo de ganhar a vida, passando a trabalhar entre frequentes idas e vindas para o país vizinho. No centro de São Paulo, mais especificamente nas ruas 25 de março e Santa Ifigênia, alguns comerciantes chegavam a pagar quem estivesse disposto a viajar ao Paraguai para trazer mercadorias, tendo em vista as vantagens diferenciais. Havia também uma ligação direta entre os próprios comerciantes de ambos os lados da fronteira, sendo que nos dois casos muitos eram libaneses e chineses, como iremos debater a seguir. Ao longo das décadas de 1980 e 1990 eram muito comuns as excursões de sacoleiros que se organizavam para trazer mercadorias de Ciudad del Este. De diversos lugares do território brasileiro, muitos ônibus se direcionavam a Foz do Iguaçu, de onde os sacoleiros cruzavam a ponte a pé, em táxis, mototáxis e ônibus de linha. Depois das compras em Ciudad del Este, valiam-se das cotas de turismo $\mathrm{O}^{7}$ para reingressar no país com as mercadorias, por vezes contratando o serviço de "laranjas" para minimizar o risco de perda das mercadorias no posto de fiscalização da Receita Federal. Muitos pequenos comerciantes, vendedores de porta em porta, camelôs, além de pessoas que se especializaram em trazer mercadorias para fornecer a outros comerciantes, frequentavam Ciudad del Este periodicamente para abastecer seus empreendimentos. 
No entanto, esse comércio nunca teve um sentido único, enquanto brasileiros atravessavam a fronteira para buscar brinquedos, eletrônicos e afins, paraguaios também levavam ao seu país outros produtos oriundos do Brasil, nesse caso, principalmente artigos de vestuário. Conforme demonstra Rabossi (2004), se em Ciudad del Este existe a figura do "laranja" brasileiro, em Foz do Iguaçu existe a figura do pasero paraguaio, que faz a passagem das mercadorias brasileiras para o outro lado do rio. Segundo o autor, este trânsito sempre foi e continua sendo bastante importante em termos de volume de mercadorias, embora as referências construídas sobre o comércio na fronteira sejam sempre no sentido inverso ${ }^{8}$. Em São Paulo, em nossa pesquisa de campo foi possível encontrar entre os migrantes paraguaios residentes há mais tempo pessoas que trabalham como representantes de vendas e agentes de compras, enviando constantemente mercadorias a todo o Paraguai através das empresas de viagens. Isso seria algo estabelecido há anos, sendo que é muito mais comum entre os migrantes residentes na Região Metropolitana de São Paulo (RMSP) enviar mercadorias para o Paraguai do que o contrário.

A trajetória de Lopes $^{9}, 60$ anos, natural de Assunção, é bem ilustrativa deste fluxo de mercadorias no sentido contrário. Ele migrou para São Paulo em 1978. Quando chegou à cidade atuava como representante de vendas autônomo: "eu já era vendedor na época e começaram a me falar que aqui era uma boca boa para vender para os paraguaios, não para o Brasil". Seu trabalho consistia em fazer compras no centro de São Paulo, principalmente artigos de vestuário, e enviá-las para Foz do Iguaçu, de onde seguiriam posteriormente para todo o Paraguai após cruzarem a fronteira em Ciudad del Este. Com pouco mais de vinte anos na época, cursava administração de empresas e esperava concluir o curso no Brasil, o que nunca ocorreu.

Seu pai era ligado ao Partido Colorado e ao presidente Federico Cháves, deposto por Stroessner exatamente no ano em que Lopes nasceu. Com o início da ditadura, seu pai chegou a tentar refugiar-se em Mato Grosso, onde foi pego e deportado, ficando dois anos preso no Paraguai. Para a família de Lopes a ascensão de Stroessner representou uma grande queda em termos de padrão financeiro e eles passaram a viver basicamente do comércio. Depois de um ano que Lopes chegou a São Paulo, montou um restaurante com o apoio de conhecidos de seu pai que haviam se exilado na cidade, ligados ao Movimento Popular Colorado (Mopoco), um dos principais grupos políticos de oposição a Stroessner organizados desde o exterior. Assim, além de representante de vendas, Lopes se tornou dono de restaurante.

Já no princípio dos anos 1980, Lopes havia alcançado uma boa situação financeira conciliando as duas atividades. Porém, o excesso de trabalho acabou Ihe causando problemas de saúde e ele vendeu o restaurante e retornou ao Paraguai. Durante quase um ano viveu apenas com os recursos que havia acumulado no Brasil, regressando no final de 1982 depois que acabou seu dinheiro. Novamente Lopes vai se dedicar a abastecer o comércio no Paraguai 
com produtos brasileiros. Quando as oficinas de costura se tornaram um nicho de trabalho para os migrantes paraguaios, ele também formou a sua própria. Alugou um espaço, investiu em máquinas e hoje um grupo de paraguaios mora e trabalha no local. Lopes se encarrega apenas de conseguir as encomendas de costura enquanto outra pessoa se encarrega de gerir a oficina. No entanto, o comércio é a principal atividade a que se dedica Lopes há mais de 30 anos.

Do lado brasileiro, a atividade dos paraguaios que enviam mercadorias ao seu país não é ilegal, do mesmo modo que em Ciudad del Este os sacoleiros brasileiros são parte constituinte da economia local através de mercados regulares. No Paraguai também existe uma imagem sobre contrabando associado ao comércio com o Brasil, mas nesse caso os produtos seriam outros. Conforme analisa Rabossi, a ideia de contrabando pressupõe a passagem pela fronteira e é a descrição de uma atividade a partir do ponto de vista de um dos territórios unidos por esta prática, pois, do outro lado da fronteira, as atividades ligadas às transações não necessariamente infringem regulamentações legais (2004, p.15). Em outra perspectiva, Rosana Pinheiro Machado (2008), refletindo sobre as categorias de formal, informal, ilegal e ilícito na rota China, Paraguai e Brasil argumenta que as mercadorias em sua vida socia ${ }^{10}$ mudam constantemente de status, na medida em que circulam e trocam de mãos, e, dependendo de onde e como circulam, ora são legais ora são ilegais. É de acordo com o espaço por onde elas circulam que recaem as regulações e as formas de controle ${ }^{11}$.

\section{Circulações migratórias: conexões libanesas e chinesas}

A Ponte da Amizade também foi caminho para diferentes fluxos migratórios que posteriormente viriam a se estabelecer em São Paulo. Além dos paraguaios, durante certo período entre os anos 1970 e 1980, a migração de sul-coreanos, de chineses e, em menor medida, de bolivianos também passava por lá. No sentido contrário, migrantes libaneses e chineses partiram de São Paulo para se estabelecer em Ciudad del Este, assim como é comum brasileiros de Foz do Iguaçu trabalharem no comércio do outro lado da fronteira. Apesar de ser a segunda maior do Paraguai, Ciudad del Este é uma cidade relativamente recente, constituída basicamente de migrantes transnacionais e principalmente internos. A sua formação como polo comercial não deriva apenas das diferenças entre as políticas econômicas implementadas nos dois lados da fronteira, mas também de pessoas que ocuparam e constituíram este lugar caracterizado pelo comércio fronteiriço.

Em especial, dois grupos de migrantes marcaram o seu desenvolvimento e têm presença bastante expressiva na cidade paraguaia: chineses e libaneses ${ }^{12}$. Também estavam na cidade de Foz do Iguaçu, na medida em que muitos estabeleceram comércio no lado paraguaio, mas muitas vezes residiam do lado brasileiro, quando não desenvolviam atividades comerciais em ambos os lados 
(RABOSSI, 2007). Sem o intuito de discutir a migração libanesa e a chinesa em si, traçamos aqui alguns indícios de sua importância nesse circuito comercial. Para além dos sacoleiros, essas dinâmicas migratórias colocaram Ciudad del Este em contato com São Paulo desde a sua formação, além de relacioná-la a outros espaços do globo.

Os migrantes libaneses se estabeleceram no comércio do centro de São Paulo desde o final do século XIX, particularmente na rua 25 de março. Quando houve a retificação e canalização do rio Tamanduateí no final do século XIX, ocuparam a área aterrada situada às margens do rio com armazéns, lojas de armarinho e de tecidos (OLIVEIRA, 2010). Foram atores importantes na formação da indústria têxtil e de confecções em São Paulo, juntamente com os judeus, constituindo muitas fábricas também na região do Brás (KONTIC, 2001). Através de vendas consignadas e do fornecimento de mercadorias a crédito por aqueles já estabelecidos na produção em São Paulo e no comércio atacadista do centro da cidade, os libaneses recém-chegados percorriam longas distâncias vendendo de porta em porta na periferia, no interior do estado, em Minas Gerais, no Paraná; e através da atuação como mascates abasteciam os comerciantes das localidades por onde passavam (OLIVEIRA, 2010).

De modo que isto também garantia aos seus patrícios que forneciam as mercadorias a crédito uma ampla circulação para seus produtos. Esses foram elementos importantes de seu estabelecimento tanto na indústria têxtil e de confecções como no comércio atacadista no centro de São Paulo. A dedicação ao comércio tão recorrente e característica entre os migrantes libaneses no Brasil, em grande medida se deve a este tipo de agenciamento no fornecimento de mercadorias a crédito e à atividade comercial como mascates (TRUZZI, 1992).

Como destaca Rabossi, foi justamente como mascates que os libaneses chegaram a Foz do Iguaçu na década de 1960 e ali se estabeleceram tendo em perspectiva o comércio fronteiriço com o Paraguai; nas palavras do autor, naquela época um "mercado virgem para os produtos brasileiros" (2007, p. 292). Eram migrantes que já haviam morado em São Paulo ou em outras cidades do sudoeste e ainda aqueles acabados de chegar do Líbano, que se instalaram em Foz do Iguaçu distribuindo artigos de confecção e tecidos produzidos na capital paulista.

De acordo com o mesmo autor, em muitas cidades de fronteira da América Latina, migrantes árabes se estabeleceram tendo em vista as oportunidades ligadas ao comércio; no caso de Foz do Iguaçu e Ciudad del Este o diferencial foi que estas oportunidades eram ligadas tanto à venda de produtos brasileiros como de artigos importados. O seu estabelecimento do outro lado da fronteira, em Ciudad del Este, a partir da inauguração da ponte, estaria diretamente relacionado aos incentivos do regime Stroessner para o comércio baseado na importação de artigos estrangeiros para reexportação (RABOSSI, 2007, p. 297).

A partir das casas de importação em Ciudad del Este vai se marcar outra forma de inserção econômica dos migrantes libaneses, de modo que diferentes 
fluxos comerciais passaram a se interconectar a partir desses espaços. Houve outra geração de migrantes libaneses que se direcionou para Foz do Iguaçu e Ciudad del Este entre 1973 e 1992 em função da guerra civil no Líbano (ARRUDA, 2007), mas que também vieram para São Paulo se apoiando nas redes de acolhida dos libaneses que já se encontravam na cidade anteriormente (BUENO e KHOURY, 2008). Se no princípio o comércio de vestuário e tecidos produzidos no Brasil era um marco da atuação dos migrantes libaneses, a partir de Ciudad del Este a importação e o comércio de artigos eletroeletrônicos e de informática vão ganhar destaque. Nos shoppings nas proximidades da Ponte da Amizade no lado paraguaio que comercializam este tipo de produtos é muito recorrente os proprietários terem origem árabe e empregarem vendedores brasileiros ou paraguaios que falam português.

Em relação à migração chinesa ${ }^{13}$, houve uma diáspora posterior à revolução comunista em 1949 quando se dispersaram por diversos países na América Latina, incluindo Paraguai e Brasil. Por ocasião da revolução comunista na China, a oposição nacionalista refugiou-se na ilha de Taiwan e de lá manteve o governo como República da China, em contraposição ao governo comunista da República Popular da China. Até hoje Taiwan é considerada uma província rebelde pelo governo chinês que não reconhece a sua autonomia. Para o governo chinês, Taiwan continua como parte do seu território de acordo com o princípio de "um país, dois sistemas", ou seja, faz parte da China apesar do sistema político diferente, a exemplo de Hong Kong e Macau.

A "questão de Taiwan" teve implicações em como se deu a migração chinesa entre o Brasil e o Paraguai. No período entre a revolução e abertura econômica chinesa em 1979, a migração a partir da China continental estava proibida pelo governo comunista. Desse modo, os chineses que migravam ou eram provenientes de Taiwan, Hong Kong e Macau, ou passavam por estes lugares antes de conseguirem chegar ao $\mathrm{Brasil}^{14}$ ou ao Paraguai. No plano diplomático, depois da revolução comunista, o Brasil havia rompido relações com Pequim e passado a reconhecer o governo de Taiwan como representante da China a partir de 1952. Esta situação perdurou até 1974 quando o governo brasileiro, seguindo as resoluções da ONU, reestabeleceu a diplomacia com a República Popular da China e, em consequência de exigência do governo chinês de Pequim, rompeu vínculo com o governo de Taiwan.

Ao mesmo tempo, o governo paraguaio desde 1957 reconhece a autonomia de Taiwan enquanto nação independente e é um dos poucos países que não mantém relações diplomáticas com o governo da China Continental. O governo de Stroessner estabeleceu relações estreitas com Taiwan que tem um grande peso nas relações diplomáticos do Paraguai. Isso a tal ponto que em Ciudad del Este uma das principais praças ostenta uma estátua de Chiang Kai-shek, principal liderança nacionalista chinesa que comandou o governo de Taiwan. Além do aspecto político, Taiwan também exerce uma grande influência econômica sobre o Paraguai. 
Essas diferenças exerceram grande peso na orientação dos fluxos migratórios de chineses entre Brasil e Paraguai, pois ao mesmo tempo em que os diferenciava, também criava uma relação entre eles. Em Ciudad del Este, conforme argumenta Rosana Pinheiro Machado (2010), os aspectos diplomáticos da "questão de Taiwan" teriam favorecido as relações associativas entre os migrantes vindos de Taiwan e houve certa 'taiwanização' dos migrantes da China continental, nos termos da autora. No Brasil, ocorreu justamente o contrário, foram os migrantes da China continental que passaram a contar com maiores facilidades em termos de serviços consulares, também são eles que apresentam maior preponderância nas associações culturais.

O elemento central que se ressalta é que, enquanto em Ciudad del Este os migrantes chineses contavam com incentivos fiscais e as relações diplomáticas entre Taiwan e Paraguai favoreciam o comércio exterior, os migrantes chineses de São Paulo estavam justamente em um contexto de restrição às importações, pelo menos até a abertura econômica brasileira no princípio dos anos 1990 . No entanto, estabeleciam o contato com o circuito comercial da fronteira por meio dos sacoleiros. Assim, na origem dos circuitos comerciais que ligam os mercados populares do centro de São Paulo à China, passando por Ciudad del Este, havia uma interconexão com os migrantes chineses que se estabeleceram no Paraguai. Quem fazia a importação estaria radicado no país vizinho, e teria sido em meados dos anos 1970 que os primeiros migrantes chineses se instalaram em galerias comerciais da rua 25 de março, trabalhando na distribuição dos artigos produzidos a princípio em Taiwan ou Hong Kong, que chegavam via Paraguai.

Essas regiões compunham, na época, os tigres asiáticos, que recebiam massivos investimentos da Europa e, principalmente, dos Estados Unidos para se desenvolverem como plataformas de exportação e assim formarem um cordão de isolamento contra o avanço do comunismo na Ásia. Também estiveram entre os tigres asiáticos a Coreia do Sul e o Japão, que no princípio de sua industrialização também empregaram largamente as cópias e falsificações como estratégia de produção. Posteriormente, com a política das zonas econômicas especiais e o processo de abertura econômica em 1979, a China assumiu um papel de destaque na produção dos mais diversos tipos de mercadorias (PINHEIRO MACHADO, 2009). Tanto o governo de Taiwan como o governo da China pósabertura estabeleceram políticas de reaproximação com seus migrantes no exterior através de associações culturais, tendo em vista a promoção de sua produção industrial e exportações (XIANG, 2007).

Ao se andar pelas ruas do centro comercial de Ciudad del Este, as marcas da influência árabe e chinesa são múltiplas e variadas. Estão lado a lado os restaurantes árabes e chineses frequentados por seus conterrâneos e as suas lojas nos shoppings visitadas pelos turistas brasileiros. A migração chinesa e libanesa é parte constitutiva das dinâmicas comerciais de Ciudad del Este, e se desenvolveu em uma relação estreita com seus conterrâneos radicados no centro de São Paulo. 


\section{Auge e declínio do circuito dos sacoleiros em Ciudad del Este}

No final dos anos 1980 já eram bastante comuns produtos originários de Taiwan e da China distribuídos nas ruas e nos centros de comércio popular. Em grande medida, esses produtos chegavam a diversos lugares do Brasil através de sacoleiros que organizavam excursões com centenas de ônibus para se abastecer em Ciudad del Este. Produtos os mais variados a preços baixos, amplamente difundidos por vendedores ambulantes, lojinhas, entre outros. Pouco a pouco, a partir disso, a expressão "do Paraguai" passou a ser usada como sinônimo de contrabando, falsificação, pirataria, baixa qualidade, mercadoria barata. Mesmo em situações que em nada remetem ao fluxo comercial em questão, frequentemente "do Paraguai" ou "paraguaio" assume uma conotação pejorativa quanto à qualidade e originalidade. No entanto, a dinâmica que em larga medida serviu de suporte na construção desse tipo de estereótipo vem se alterando gradativamente ao longo dos últimos vinte anos. A partir da abertura econômica do Brasil diversos fatores têm contribuído para seu decréscimo.

A paraguaia Solange, 47 anos, trabalhou no circuito entre Ciudad del Este e São Paulo como sacoleira ao longo de todo este período, acompanhando seu auge e declínio. Porém, diferentemente da maioria dos sacoleiros, ela trabalhava nos dois sentidos, levando e trazendo mercadorias entre São Paulo, Ciudad del Este e Assunção. Em 1986, aos 19 anos de idade migrou para São Paulo, atuava como costureira na oficina de uma prima casada com um coreano. Solange já tinha experiência profissional no setor desde os 15 anos, por isso sua prima foi buscá-la no Paraguai. Durante quatro anos ela trabalhou e morou em duas diferentes oficinas de costura: na primeira, com a sua prima e, em uma segunda, de propriedade de um coreano, na qual era a responsável pela oficina. No início de 1990, engravidou e regressou à sua cidade natal, capital do Paraguai.

Depois do nascimento do seu filho, não voltou a trabalhar com costura e nem mesmo a morar no Brasil. Em 1992, Solange começou a trabalhar como sacoleira, no princípio trazendo artigos eletrônicos e brinquedos para comerciantes na famosa Galeria Pagé, conjunto de dois prédios localizado nos arredores da rua 25 de março, em São Paulo, conhecida desde os anos 1970 pela distribuição de artigos importados. Naquela época, enquanto seu filho ficava com a avó em Assunção, ela vivia grande parte do tempo na estrada. Passou a aproveitar as viagens de volta para levar mercadorias no sentido contrário, de acordo com as encomendas de comerciantes de Assunção. Até mesmo para a Argentina ela viajava em busca de mercadorias para seus clientes.

Tem gente que pergunta: ué, a gente está trazendo do Paraguai, vocês estão levando daqui?! Mas o que a gente leva não é eletrônica, são estas velas que eu falo, sapatilha para dança, muita coisa, roupa, fita, tinta, cestas para máquina de lavar, coisa de cozinha, de fogão. Muitas outras 
coisas que não temos no Paraguai, então a gente é obrigado a levar daqui pra lá. Em termos de eletrônicas, trazemos tudo de lá. (...) Então era tipo um intercâmbio, comprava roupa aqui no Brás e levava para Assunção e de lá de Ciudad del Este eu trazia eletrônica. Eu viajava para a Argentina e trazia roupa também, porque roupa Argentina se vende muito no Paraguai. Fiquei nesta daí já vai fazer 25 anos.

Solange não trabalhava com recursos próprios, os comerciantes da região da 25 de março lhe forneciam o dinheiro e ela recebia uma comissão por cada mercadoria que conseguisse trazer. Estes comerciantes também pagavam sua hospedagem em São Paulo em um hotel da Av. Rio Branco. Nas proximidades deste hotel, até hoje duas linhas de ônibus regulares das empresas paraguaias Sol del Paraguay e NSA têm partidas diárias para Assunção. Através delas, muitas mercadorias brasileiras são enviadas ao Paraguai.

De acordo com Solange, nos últimos anos trazer mercadorias de Ciudad del Este tem ficado cada vez mais difícil. Ela continua levando mercadorias para o Paraguai e não mais o contrário. Vários fatores têm contribuído para o decréscimo do circuito dos sacoleiros a partir da Ponte da Amizade. Muitas casas de importação foram abertas no centro de São Paulo em meados da década de 1990 , sendo que em alguns casos migrantes libaneses e chineses se transferiram para a cidade. De fato, a migração chinesa para a cidade cresceu bastante nos últimos anos. As galerias de comércio atacadista no centro se multiplicaram e excursões de sacoleiros que antes se direcionavam para o Paraguai agora se encaminham para a capital paulista (FREIRE DA SILVA, 2014).

Tanto os estudos de Fernando Rabossi $(2004,2012)$ como de Rosana Pinheiro Machado (2009) apontam para um declínio progressivo no circuito dos sacoleiros em Ciudad del Este. De acordo com Rabossi (2012), tomando como parâmetro o fluxo de ônibus para Foz do Iguaçu, o turismo de sacoleiros em direção ao Paraguai teve seu auge entre 1994 e 1995, desde então tem acompanhado um decréscimo ano após ano. $O$ autor aponta algumas razões para esta diminuição, como o acordo regional do Mercosul e a redução das taxas para importação em 1995. Ao mesmo tempo, em São Paulo houve uma mudança de escala nestes fluxos comerciais e a cidade vem assumindo centralidade nesta dinâmica, a ponto de alguns locais conhecidos como "feira do Paraguai" em Brasília e Caruaru, por exemplo, serem abastecidos atualmente em São Paulo (RABOSSI, 2012, p. 65). Hoje, as mercadorias chegam diretamente através dos Portos de Santos, Paranaguá e Rio de Janeiro e são distribuídas no centro da capital paulista sem passar por Ciudad del Este.

Não se trata de dizer que o circuito de sacoleiros para Ciudad del Este não permanece. Ainda existem excursões que se dirigem para lá regularmente, com pessoas em busca de mercadorias, sobretudo artigos de informática e eletrônicos. Das imediações da Rua 25 de março, ainda sai um ônibus para Foz do Iguaçu 
todos os dias da empresa TransMuleke, conhecido pelos migrantes paraguaios como o ônibus dos sacoleiros. Porém, o fluxo de ônibus que partem atualmente em direção ao Paraguai é bem menor. De acordo com Solange, antigamente formavam-se comboios de até cem partindo em conjunto para evitar assaltos e minimizar os riscos de fiscalização. O controle sobre o fluxo de ônibus para Foz do Iguaçu atualmente é bem maior, principalmente sobre os ônibus fretados, o que também contribuiu para a diminuição do circuito dos sacoleiros.

\section{Conclusão}

As imagens que se tem no Brasil sobre o Paraguai foram, em grande medida, construídas a partir de representações sobre a dinâmica comercial de Ciudad del Este. Em especial, a repercussão midiática da atividade dos sacoleiros contribuiu para que se criasse a associação entre "do Paraguai" e "paraguaio" a contrabando, falsificação, baixa qualidade. Trata-se de uma representação extremamente naturalizada e banalizada no Brasil, à qual os migrantes paraguaios estão sujeitos e que impede uma percepção mais ampla sobre sua cultura e história por parte dos brasileiros. Com estes estereótipos, tomam-se alguns elementos muito específicos e historicamente situados para uma caracterização ampla e distorcida sobre um país e sua população.

Ao analisarmos o processo de formação destas dinâmicas comerciais, vemos os múltiplos aspectos que concorrem em seu desenvolvimento. Ciudad del Este e São Paulo têm uma ligação histórica na constituição destes fluxos comerciais. No entanto, os preconceitos associados ao comércio fronteiriço impedem a percepção dos fluxos que se dão no sentido contrário desde o início da formação de Ciudad del Este: quer através dos libaneses que chegaram à cidade para vender artigos de vestuário provenientes da cidade de São Paulo, quer dos próprios paraguaios que ainda hoje buscam mercadorias na região central desta cidade para enviar ao Paraguai. Da mesma forma, obscurece como esta dinâmica tem sofrido profundas alterações ao longo dos últimos vinte anos e o lugar de centralidade que a cidade de São Paulo vem assumindo nestes circuitos comerciais.

Contrabando e falsificação são formas de caracterizar disputas econômicas e comerciais que estão ligadas com a própria massificação do consumo e à globalização dos processos econômicos. Tomá-las como características da atuação de um grupo particular de acordo com a sua origem - seja de paraguaios, libaneses, chineses ou brasileiros - é um erro que justamente obscurece o âmbito das disputas de mercado nas quais estas categorias são construídas. 


\section{Notas}

1 - O link abaixo traz um registro oficial em vídeo sobre a inauguração da Ponte da Amizade, nele se esboça o turismo de elite direcionado às cataratas do Iguaçu naquele período, às atividades econômicas da região, bem como o aperto de mãos entre os governantes militares dos dois países, Alfredo Stroessner e Castelo Branco, em plena Ponte da Amizade, e os detalhes sobre a construção da mesma. Disponível em: <https://www.youtube.com/watch?v=VnyWeEVzg7U>.

2 - Para maiores informações, ver o site: <http://paraguaiteete.wordpress.com/>. Acesso em: 30 jun. 2014.

3 - Há outras cidades no Brasil que tiveram sua economia dinamizada pelo comércio fronteiriço: Brasileia, no Acre, faz fronteira com a zona franca de Cobija, Bolívia, muitos brasileiros do norte do país vão à capital do Departamento de Pando para se abastecerem de bebidas, perfumes, eletrodomésticos, etc; Corumbá, no Mato Grosso, e Pueto Quijarro, também na Bolívia; no estado do Paraná,Guaíra e Salto del Guaíra no Paraguai... Em função do comércio fronteiriço o estabelecimento de Free Shops em cidades gêmeas de fronteira tem se multiplicado nos últimos anos. Não apenas no Brasil, em diversos lugares no mundo o comércio baseado em vantagens diferenciais entre fronteiras é um fenômeno recorrente.

4 - As duas sessões seguintes do texto foram em parte baseadas em minha tese de doutorado, tendo sido trabalhadas mais detalhadamente em Freire da Silva (2014).

5 - Fonte: Gobernación del Alto Paraná, Paraguay. Disponível em: <http://web.altoparana.gov. py/v1/cde.html>. Acesso em: 7 jul. 2014.

6 - Ver: "O Estado de São Paulo" - O presidente Vargas recebe no Paraguai as maiores homenagens (03/08/1941).

7 - Trata-se do valor máximo de mercadorias que podem ser trazidas sem a necessidade de declaração e pagamento de imposto.

8 - Em outro artigo Fernando Rabossi (2008) desenvolve uma análise acerca dos produtores de sulanca de Pernambuco que comercializam seus produtos em Ciudad del Este.

9 - Os nomes utilizados para os entrevistados são fictícios.

10 - Por vida social de uma mercadoria, entende-se todo o processo que envolve a ação humana na confecção e distribuição de uma mercadoria. Isto é, do trabalho envolvido para a produção propriamente às leis e ações que regulamentam a situação de determinada mercadoria em um território. Ver: Appadurai (2004).

11 - Ressalta-se ainda que apesar dessa dinâmica ser popularmente conhecida como contrabando, em termos jurídicos trata-se do descaminho, que consiste em importar um produto sem o recolhimento devido do imposto total ou parcial, enquanto o contrabando seria a importação de produtos proibidos, descritos como ilegais.

12 - Migrantes sírios, em larga medida, também ocuparam os mesmos nichos econômicos e territórios nos quais estão presentes os libaneses, no entanto, não foram tão numerosos quanto os últimos. A literatura utilizada como referência aqui trata, sobretudo, dos libaneses.

13 - A migração chinesa para o Brasil tem mais de 200 anos, sendo o primeiro grupo de migrantes asiáticos a terem desembarcado no país em 1810, na cidade do Rio de Janeiro para trabalhar nas plantações de chá. Ainda na segunda metade do século XIX, houve outra leva de migrantes chineses cuja vinda foi acordada pelos governos de ambos os países. No entanto, os fluxos mais significativos começaram na década de 1930, em função da guerra entre China e Japão (1931-1945), e principalmente a partir de 1949 com a revolução comunista. Para um estudo detalhado sobre os primeiros migrantes chineses no Brasil até períodos mais recentes, ver Shu Chang-Sheng (2012), José Roberto Teixeira Leite (1999), Marcos de Araújo Silva (2008), Daniel Bicudo Véras (2008) e Douglas Toledo Piza (2012). 
14 - Algo bem documentado por Shu Chang-Sheng (2012) ao ilustrar com relatos de migrantes qintianeses (província de Zhejiang, China) a dificuldade em se conseguir um visto para o Brasil naquela época.

\section{Referências}

APPADURAI, Ajurn. Introduction: commodities and the politics of value. In: APPADURAI, Ajurn. The social life of things: commodities in cultural perspective. Cambridge, Cambridge Univesity Press, 2004, p. 3-63.

ARRUDA, Aline Maria Thomé. A presença libanesa em Foz do Iguaçu (Brasil) e Ciudad del Este (Paraguai). Dissertação (Mestrado em Ciências Sociais) Instituto de Ciências Sociais, Universidade de Brasília. Brasília, 2007.

BUENO, Marielys Siqueira; KHOURY, Dolly. Redes de acolhimento para a imigração libanesa em São Paulo. Anais do XVI Encontro Nacional de Estudos Populacionais. Caxambu, 2008.

CHANG-SHENG, Shu. Rio de Janeiro recebeu os primeiros imigrantes chineses. Disponível em: <http://oestrangeiro.org/2012/04/12/chineses-no-rio-de-janeiro/>. Acesso em: 10 fev. 2014.

FREIRE DA SILVA, Carlos. Das calçadas às galerias: mercados populares no centro do Centro de São Paulo. Tese (doutorado em sociologia). Faculdade de Filosofia, Letras e Ciências Humanas, Universidade de São Paulo. São Paulo, 2014.

KONTIC, Branislav. Aprendizado e metrópole: a reestruturação produtiva da indústria do vestuário em São Paulo. Dissertação (mestrado em sociologia). Faculdade de Filosofia, Letras e Ciências Humanas, Universidade de São Paulo. São Paulo, 2001.

LEITE, José Roberto Teixeira. A China no Brasil: influências, marcas, ecos e sobrevivências chinesas. Campinas, Ed. Unicamp, 1999.

MENEZES, Alfredo da Mota. A herança de Stroessner: Brasil e Paraguai 1955-1980. Campinas: Papirus, 1987.

OLIVEIRA, Lineu Francisco de. Mascates e sacoleiros: empreendedores que construíram uma região - Rua 25 de março desde 1865 fazendo história. São Paulo: Scortecci, 2010.

PALAU, Tomás. El marco expulsivo de la migración paraguaya. Migración interna y migración externa. In: HALPERN, Gerardo (org.). Migrantes: perspectivas (críticas) en torno a los procesos migratorios del Paraguay. Assunção: Ápe Paraguay, 2011.

PINHEIRO-MACHADO, Rosana. "China-Paraguai-Brasil: uma rota para pensar a economia informal". Revista brasileira de ciências sociais, v. 23, n. 67, p. 117-133, 2008.

PINHEIRO-MACHADO, Rosana. Made in China: produção e circulação de mercadorias no circuito China-Paraguai-Brasil. Tese de doutorado, UFRGS, Porto Alegre, 2009.

PINHEIRO-MACHADO, Rosana. Uma ou duas Chinas? A "questão de Taiwan" sob o ponto de vista de uma comunidade chinesa ultramar (Ciudad del Este, Paraguai). In: Civitas, v. 10, n. 3, p. 468-489, 2010.

PIZA, Douglas Toledo. Um pouco da mundialização contada a partir da região da rua 25 de Março: migrantes chineses e comércio "informal". Dissertação (Mestrado em Sociologia) Faculdade de Filosofia, Letras e Ciências Humanas, Universidade de São Paulo. São Paulo, 2012.

RABOSSI, Fernando. Nas ruas de Ciudad del Este: vidas e vendas num mercado de fronteira. Tese de doutorado. Museu Nacional, Universidade Federal do Rio de Janeiro, 2004. 
RABOSSI, Fernando. Árabes e muçulmanos em Foz do Iguaçu e Ciudad del Este: notas para uma re-interpretação. In: SEYFERTH, G; PÓVOA, H; ZANINI, M. C.; SANTOS, M.. (Orgs.). Mundos em Movimento: Ensaios sobre migrações. Santa Maria: Editora da Universidade Federal de Santa Maria, 2007, p. 287-312.

RABOSSI, Fernando. En la ruta de las confecciones. Critica en Desarollo. In: Revista Latino Americana de Ciencias Sociales, v. 2, p. 151-171, 2008.

RABOSSI, Fernando. Ciudad del Este and Brasilian circuits of commercial distribution. In: MATHEWS, Gordon; RIBEIRO, Gustavo Lins and VEGA, Carlos Alba (Eds). Globalization from Below: The world's other economy. New York: Routledge, v. 1, p. 54-68, 2012.

SILVA, Marcos de Araújo. Guanxi nos trópicos: um estudo sobre a diáspora chinesa em Pernambuco. Dissertação de mestrado, Recife, Universidade Federal de Pernambuco, 2008.

SILVA, Ronaldo Alexandre do Amaral e. Brasil-Paraguai - marcos da política pragmática na reaproximação bilateral, 1954-1973: um estudo de caso sobre o papel de Stroessner e a importância de Itaipu. Dissertação (Mestrado em Relações Internacionais), Universidade de Brasília, Brasília, 2006.

TRUZZI, Oswaldo. De mascates a doutores: sírios e libaneses em São Paulo. São Paulo, Idesp/ Sumaré, 1992.

VERÁS, Daniel Bicudo. As diásporas chinesas e o Brasil: a comunidade sino-brasileira em São Paulo. Tese (Doutorado em Ciências Sociais), PUC, São Paulo, 2008.

XIANG, Biao. A new mobility regime in the making: what does a mobile China mean to the world? In: Idées pour le débat, n. 10, p. 1-19, 2007.

\title{
RESUMO
}

A dinâmica comercial de Ciudad del Este é base para muitas representações sobre o Paraguai no Brasil. São imagens pejorativas que associam "do Paraguai" e "paraguaio" a "contrabando" e "falsificação" e pouco informam sobre o próprio desenvolvimento do comércio fronteiriço. Neste artigo, buscamos problematizar estas representações analisando como se deu a formação da dinâmica comercial a partir da reaproximação diplomática entre os dois países, do turismo de sacoleiros e dos fluxos migratórios que ligam Ciudad del Este e São Paulo.

Palavras-chave: comércio fronteiriço; sacoleiros; Ciudad del Este.

\begin{abstract}
The commercial dynamics of Ciudad del Este is the basis for many representations of Paraguay in Brazil. These are pejorative images that associate "from Paraguay" and "Paraguayan" with "smuggling" and "fake" and tell nothing about the development of border trade. In this article, we seek to discuss these representations analyzing the development of the trade dynamics from the diplomatic rapprochement between the two countries, the "sacoleiros" tourism and the migratory flows linking Ciudad del Este and São Paulo.
\end{abstract}

Keywords: border trade; "sacoleiros"; Ciudad del Este. 


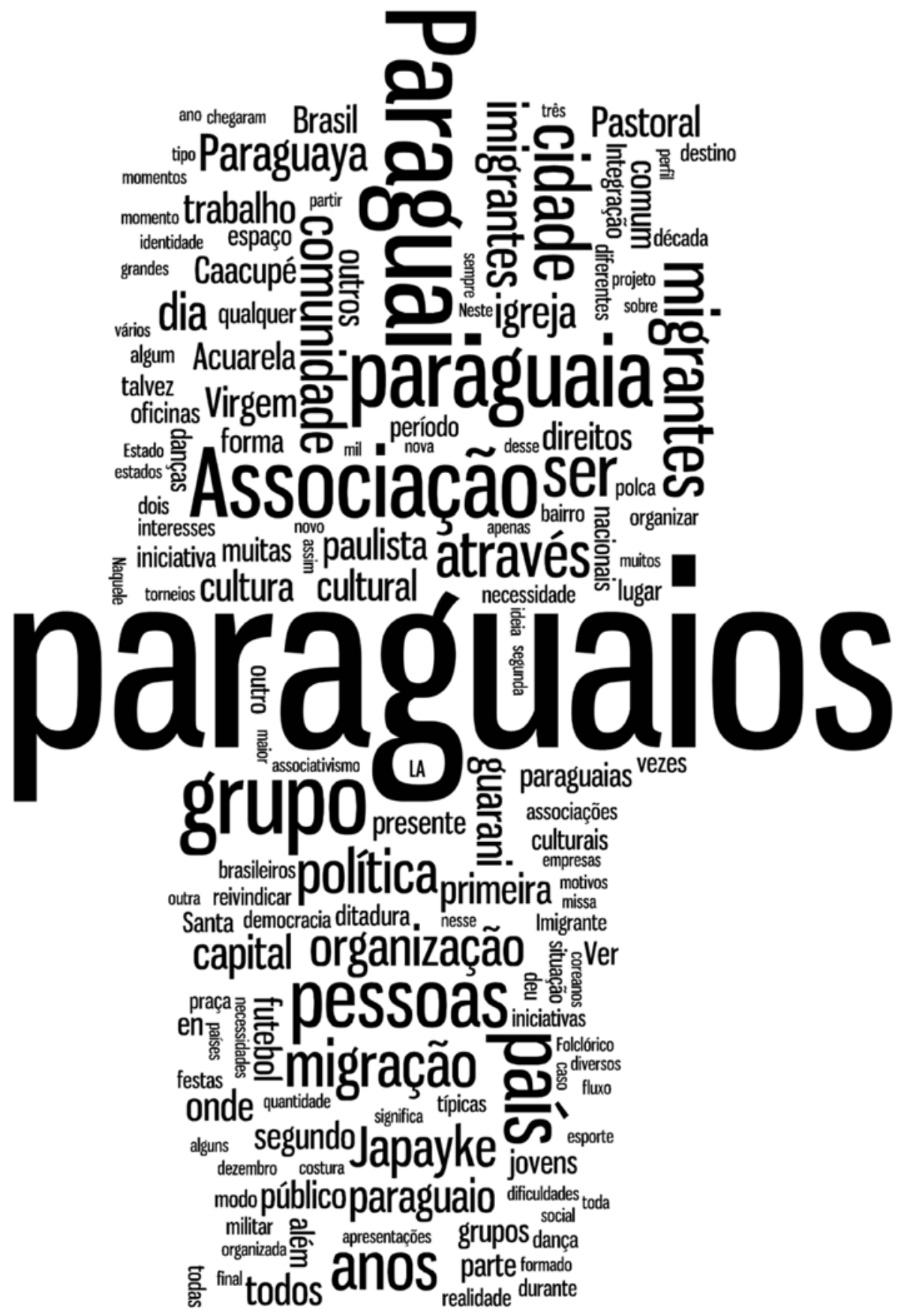


